\title{
Performance improvement of hydraulic lime based grouts for masonry consolidation - An experimental study
}

\author{
L.G. Baltazar ${ }^{1}$, F.M.A. Henriques ${ }^{1}$, M.T. Cidade ${ }^{2}$ \\ ${ }^{I}$ Department of Civil Engineering, Nova University of Lisbon, Portugal \\ ${ }^{2}$ Department of Materials Science, Nova University of Lisbon, Portugal
}

\begin{abstract}
Grouting is a currently repair technique for consolidating and strengthening old masonry structures. Grouts can be seen as mixtures of binder with water, admixtures and/or additives, which should present low viscosity and high penetrability. The grout specification involves the knowledge of the flow capacity within the masonry inner core and physic-chemical compatibility with the original materials present in the historic structures. Nevertheless, the grout properties are affected by a large number of parameters, including binder type and composition, mixing procedure, admixture type and dosage, environmental conditions, like temperature that may lead to different grout injection capacities, as reported as reported by Eriksson et al and Fernàndez-Altable et al. This paper deals with the effect of environmental temperature over superplasticised hydraulic lime-based grouts with partial replacement of lime by silica fume. Grout performance was analysed in fresh and hardened state by testing its rheological and mechanical behaviour, as well as its hydration reactions kinetics. In spite of the considerable amount of information that exists for cement based mixtures with superplasticisers, there is little information about the effects of superplasticisers when used in natural hydraulic lime mixtures proportioned with silica fume. This study aims to contribute to better understand the behaviour that superplasticised hydraulic lime grouts present under different temperatures. The results showed that hydraulic lime grouts performance could be improved, regarding rheological parameters and strength capacity if they are properly design and a suitable processing temperature were ensured.
\end{abstract}

Keywords: hydraulic lime grout, superplasticiser, silica fume, rheology, thermogravimetry, temperature, masonry consolidation. 


\section{Introduction}

Multiple leaf stone masonry walls are a construction type in many urban centres worldwide and they can be characterized by its specific vulnerability, both under vertical and horizontal loads [1]. This masonry typology is made of two resistant external stone leaves and an inner core filled by small stones, sand, mortar or other kind of unbounded material [2]. The absence of cohesion among masonry elements, the existence of voids and cracks as well as the poor connection between leaves lead to masonry walls with non-monolithic behaviour.

Injection grouting is a currently repair technique for rehabilitation, restoration and strengthening of masonry structures. Grout injection allows an increase in masonry compactness and creates bonds between the internal and external leaves, therefore improving the masonry mechanical strength and monolithic behaviour. Grouts for injection should be adequately designed to achieve the best performance from an injectability and durability point of view. This study deals with the coupled effect of polycarboxylate-based superplasticiser (SP) and temperature on rheological behaviour, mechanical strength and hydration kinetics of grouts based on hydraulic lime proportioned with silica fume (SF). The grout properties are affected by a large number of parameters, including binder type and components, mixing procedure [3], admixture type and dosage and environmental conditions, such as temperature that may lead to different grout injection capacities, as reported by Eriksson et al and Fernàndez-Altable et al $[4,5]$. A suitable grout composition, together with the flow capacity and the ability to fill the voids and cracks, will regulate the injection quality.

In order to improve the grout performance, the selection of grout component should also take into account the rheological properties, flow time, strength, among others. This means that simple binder and water formulations are inadequate to achieve the desired performance. In a previous experimental investigation [6], the effect of different admixtures and pozzolans on properties of hydraulic lime grouts have been investigated. According to these experimental results [6] the presence of SF together with SP allowed a significant improvement in the fresh grout behaviour. $\mathrm{SF}$ is an ultrafine powder from electrometallurgy industry that works as pozzolan when used in conjunction with cementitious binders. However, these finer particles are the source of additional surface area resulting in an increase of contact forces among solid particles requiring the presence of admixtures to minimize this problem, like SP. SP is a dispersant admixture whose action is based on repulsive forces; from a chemical point of view a SP is a surface active agent that acts on the binder particles by means of electrostatic charges and/or attaching long polymer chains over the particles, creating a repulsion between them [7, 8]. Thus, through SP action an improvement of rheological parameters is expected, such as reduction of plastic viscosity and yield stress. From a practical point of view, yield stress is associated with the minimum stress that is necessary to apply for the suspension to start flowing. On the other hand, plastic viscosity represents the flow resistance once flow is initiated. A low plastic viscosity means that the suspension flows easily whereas for high plastic viscosity, which results from excessive colloidal interactions between suspension particles, the flow will be much more difficult.

Other major issue on rheology of cementitious suspensions is the time-dependent properties (thixotropic behaviour); this means that in the case of hydraulic lime 
suspensions the viscosity depends not only on the shear rate applied to the sample but also on the time for which the suspension has been subjected to shearing. As the suspension is sheared, the weak physical bonds among particles are ruptured and the network among them breaks down into separate agglomerates (structural breakdown). If the suspension is at rest, the particles will start to flocculate into agglomerates again (structural build-up), leading to a workability loss. These structural changes are dominant and reversible but only on short period of time, which also depend on grout temperature [9]. In the field, the grout injection may occur under different environmental conditions, which may lead to different grout injection performance. Thus, factors like temperature and time are determinant in grout injection performance.

Natural hydraulic lime plays a role of great importance in the rehabilitation of historic structures, due to its chemical and physical properties being closer to those of the pre-existing materials in old masonries [10]. Nevertheless, hardly any studies have been done in the filed of natural hydraulic lime grouts $[3,6,11]$. It is clear, however, that a better understanding of the basic principles that govern the both fresh and hardened state properties of hydraulic lime-based grouts are necessary in order to enable a composition optimisation for masonry consolidation. Thus, for that purpose some guidelines are presented. Rheological measurements were used to investigate the effects of SF, polycarboxylate-based SP and water dosage on hydraulic lime grout properties. The workability behaviour was characterized by the rheological parameters yield stress and plastic viscosity, as well as the procedure of funnel flow time (Marsh cone test). A study was also developed which aims at contributing to better understand the flow behaviour of hydraulic lime grouts under different temperatures. The effect of temperature on the loss of fluidity is of major importance, in order to know the limitations during mixing and placement (injection). An attempt to find the temperature limit that isolates the thixotropy effect from hydration reactions was also made. This is important for the prediction of thixotropic behaviour with the normal variation of temperature in different seasons of the year. In addition, the influence of environmental conditions on grout hydration by means of thermogravimetric analyses of grouts with the same composition was performed. Thermogravimetry (TG) and derivative thermogravimetry (DTG) were used as tools to evaluate the effect of temperature over the hydration kinetics with ageing.

The results summarised in this paper are part of a vast study and precede the analysis of the performance of those grouts when injected into different porous media that simulate old masonry walls [12].

\section{Experimental details}

\subsection{Materials}

The experimental program was carried out using grouts made with natural hydraulic lime. The hydraulic lime used is a EN459-1:2010 NHL5 produced in Portugal by Secil-Martingança. A commercially available SF was used, namely undensified silica fume produced by MAPEI. The SP based on polycarboxylate (Glenium Sky 617) produced by BASF was used. This SP belongs to the third generation whose repulsion is a combination of coupled steric and electrostatic effects, known as electrosteric repulsion. 


\subsection{Mixing procedures}

The hydraulic lime grouts were prepared at room temperature $\left(20 \pm 2^{\circ} \mathrm{C}\right)$ and a relative humidity of $60 \pm 5^{\circ} \mathrm{C}$. For the preparation of grouts ordinary tap water was used. SF and dry hydraulic lime were hand mixed to ensure a homogeneous distribution before the beginning of the mechanical mixing. The mixture procedure adopted was the following [3]: the whole powder (lime + silica fume) is added to $70 \%$ of total mix water and mixed for 10 minutes. The remaining water (with diluted SP) is added within 30s (without stopping the mixer). After all materials had been added, the mixture was maintained for an additional 3 minutes at $800 \mathrm{rpm}$.

\subsection{Rheological design}

\subsubsection{Marsh cone test}

The rheology of grouts can be also characterized by the Marsh cone test, according to standard ASTM C939-02. Based on this standard the measurement of flow time is connected to the grout fluidity. It means that longer the flow time, the lower is the grout fluidity. This test enables a grout design regarding several factors like SP dosage, among others. Thus, the Marsh cone test was used to optimise the amount of $\mathrm{SP}$ and SF replacement dosage. A volume of 1,000 $\mathrm{ml}$ of grout was placed into the cone and the flow time (expresses in seconds) required for $800 \mathrm{ml}$ of grout to flow out was measured. The environmental conditions of the laboratory were characterized by $60 \% \pm 5^{\circ} \mathrm{C}$ relative humidity and a temperature of $20 \pm 2^{\circ} \mathrm{C}$. The Marsh cone test was made for different resting time values: 5, 15 and 25 minutes after grout preparation.

\subsubsection{Rheological measurements}

Rheological proprieties were evaluated with a Bohlin Gemin HR $^{\text {nano }}$ rotational rheometer, equipped with a plate-plate geometry (with $\varnothing=40 \mathrm{~mm}$ ) and a gap of $2 \mathrm{~mm}$. The grout samples were analysed $10 \mathrm{~min}$ after the mixing process had ended. In all measures the rheological protocol adopted was the following: a pre-shearing stage of $60 \mathrm{~s}$ at shear rate of $1 \mathrm{~s}^{-1}$ followed by $60 \mathrm{~s}$ at rest was applied. Then, the shear rate was increased from 0 to $300 \mathrm{~s}^{-1}$ and an analogous decreasing from $300 \mathrm{~s}^{-1}$ to rest was applied. The effect of temperature on rheological properties was studied over a range of 5 to $40^{\circ} \mathrm{C}$. Thus, a fridge and a climatic chamber were used to maintain the temperature of the materials, as well as the mixing equipment at the desired temperature. However, the mixing was made at room temperature for practical reasons. All rheological measurements were performed at the desired temperatures which were maintained by means of temperature unit control of the rheometer. The procedure enabled the determination of the flocculation area, which is related to the grout workability loos during its hydration.

The fresh grout properties can be used as a control factors to know if a grout is suitable to be injected, since a smaller yield stress and plastic viscosity means an easier injection process with lower pressures. The results were interpreted in the framework of rheology of suspension, so knowing the behaviour of hydraulic lime grouts as a shear-thinning fluid [6]; it was chosen to adopt the modified Bingham model eqn. (1) to describe the grout rheological behaviour and to determine the plastic viscosity and yield stress [13]:

$$
\tau=\tau_{0}+\eta_{p} \times \dot{\gamma}+c \times \dot{\gamma}^{2}+c
$$


where $\tau$ is the shear stress $(\mathrm{Pa}), \tau_{0}$ is the yield stress $(\mathrm{Pa}), \eta_{p}$ is the plastic viscosity (Pa.s), $\dot{\gamma}$ is the shear rate and $c$ is a constant.

\subsubsection{Mechanical strength}

In order to determine the mechanical characteristics of the formulated grouts, the compressive strength was evaluated. Prismatic grout samples $(160 \times 40 \times 40 \mathrm{~mm})$ were cured in a controlled atmosphere at $20 \pm 2^{\circ} \mathrm{C}$ and $60 \pm 5 \%$ relative humidity until the age of the compressive test. The compressive strength test was conducted at the maturity age of 28 days. A pre-load of $50 \mathrm{~N}$ was first applied before data collection commenced at a compression rate of $0.7 \mathrm{~mm} / \mathrm{min}$ to failure, using a Z050 Zwick mechanical test machine with $5 \mathrm{kN}$ capacity.

\subsubsection{Thermogravimetry}

The TG analyses were performed using a NETZSCH 449 F3 Jupiter thermogravimetric analyzer. The experimental conditions were: $\mathrm{N}_{2}$ gas dynamic atmosphere $(40 \mathrm{ml} / \mathrm{min})$; heating rate $\left(40^{\circ} \mathrm{C} / \mathrm{min}\right)$ and an alumina top-opened crucible. The samples were heated in the range of 40 to $1200^{\circ} \mathrm{C}$ at a constant rate. The calcium hydroxide $\left(\mathrm{Ca}(\mathrm{OH})_{2}\right)$ and calcium carbonate $\left(\mathrm{CaCO}_{3}\right)$ were estimated from the mass loss measured in the DTG curve. The TG test was conducted at the maturity age of 7, 14 and 28 days. Each sample was maintained in a controlled atmosphere at desired temperature of $\left(5,20\right.$ and $\left.40^{\circ} \mathrm{C}\right) \pm 2^{\circ} \mathrm{C}$ and relative humidity of $(50,60$ and $20 \%) \pm 5 \%$, respectively.

\section{Results and discussion}

\subsection{Marsh cone test}

The Marsh cone test was used to study the fluidity loss of different grouts with time as recommended by Aitcin [14]. This test gives the fluidity in terms of the time needed for a grout sample flow thought the cone, which is proportional to the fluidity of the grout (viscosity). The Marsh cone test is a simple test which can be used to achieve the saturation point or optimum dosage of SP that corresponds to the dosage beyond which any addition of SP does not change the flow time. The results are present in Figs. 1 and 2.
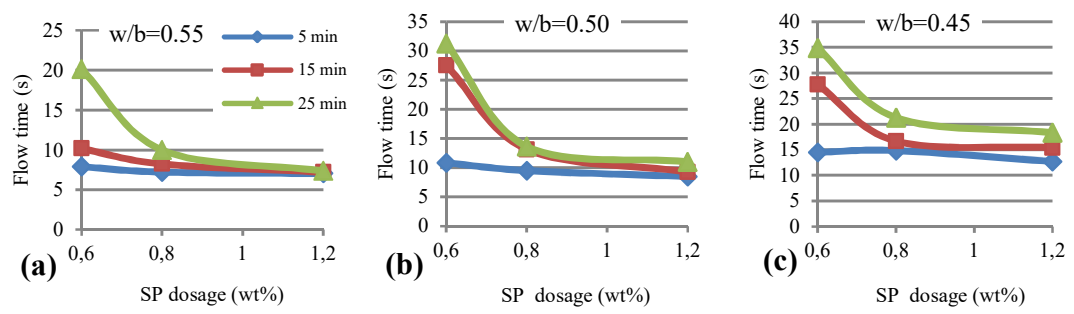

Figure 1: Flow time for 5, 15 and 25 minutes after grout preparation for different superplasticiser dosage and water/binder ratios analysed: (a) $w / b=0.55$, (b) $w / b=0.50$ and (c) $w / b=0.45$.

Concerning the dosages of SP that were tested: $0.6 \%, 0.8 \%, 1 \%$ and $1.2 \%$ by mass of binder. For a grout with $0.6 \%$ of SP, the flow at $25 \mathrm{~min}$ is too high. Moreover, the flow time is reduced with increase of w/b ratio, however simple addition of water to make the grout more fluid is an inappropriate option because a higher water/binder ratio will weaken the grout in the hardened state, and it will 
increase the shrinkage deformations and increase the free water amount that also contributes to instability phenomena [15]. It can be observed in the Fig. 1 that there is a trend in the flow curves with the increase of SP dosage, as expected, the flow times decrease with an increase in the SP dosage until the saturation point $(\mathrm{SP}=0.8 \%)$ and afterwards it remains unchanged. The saturation point appears to correspond to the maximum degree of dispersion of the grout particles. This means that the SP dosage above this point will not improve the fluidity, according to other authors [15] when a high SP concentraction is used a reverse effect can be obtained. This phenomenon is called depletion attraction, which is caused by an excessive concentration of SP in the liquid phase that will be the source of an osmotic pressure over the binder particles forcing the particles to flocculate and cause negative effects, such as stability problems (segregation and bleeding). Interesting point is that the saturation point is practically unaffected by the range of $\mathrm{w} / \mathrm{b}$ ratio studied. Based on the desire to achieve a low plastic viscosity value, it was decided to use a SP dosage of $0.8 \%$ by mass of binder and to apply the same dosage to all grouts for reasons of uniformity and preparation simplicity.

In order to reduce the grout plastic viscosity, the dosage of SF was tested, also using the Marsh cone. Fig. 2 presents the flow time results for different SF dosages analysed, with constant SP dosage of $0.8 \%$.
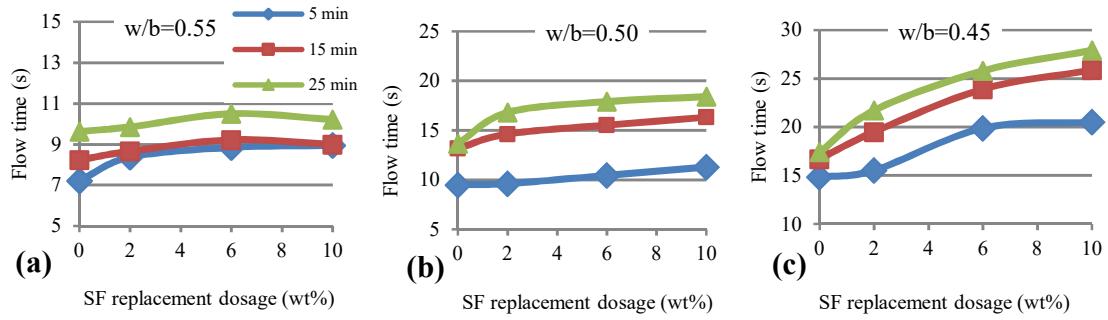

Figure 2: Flow time for 5, 15 and 25 minutes of resting time, for different silica fume dosages and water/binder ratios analysed: (a) $\mathrm{w} / \mathrm{b}=0.55$, (b) $\mathrm{w} / \mathrm{b}=0.50$ and (c) $\mathrm{w} / \mathrm{b}=0.45$.

For SF dosage higher than $2 \%$, the grout flow time tends to increase for all w/b ratios tested. It is known that SF presents a tendency to agglomerate and increase the water demand. SF is much finer than hydraulic line particles, even in the presence of $\mathrm{SP}$, the amount of SP available per surface area decreases, resulting in a more viscous grout. Another aspect that is evident in Fig. 2(a) it is the flow time shows a smaller variation for different resting times tested than other smaller one $\mathrm{w} / \mathrm{b}$ ratios analysed. This behaviour can be attributed to an excess of water, which contributes to instability phenomena. Instability phenomena such as dynamic and static segregation can occur; the dynamic segregation is related with lower homogeneity during injection when binder particles tend to settle down causing a stratified flow, whereas the static segregation is related with bleeding that occurs after the grout is in-place. These instability phenomena may be occurring during the Marsh cone test. As can be seen in Fig. 2(a), the flow time is almost constant; this is caused by the phase separation effect, in which lime and silica fume tend to stay adhered to the cup walls while only the liquid phase flows through the Marsh cone, which leads to an almost Newtonian behaviour (constant viscosity). 


\subsection{Mechanical Strength}

The grout compressive strength is of great importance, since the behaviour of hardened grout has a determinant effect on the mechanical properties of the grouted masonry. In order to check the influence of SP, SF and w/b ratio on compressive strength a campaign were undertaken following standard EN 196-1. The variations on compressive strength of grouts at the maturity age of 28 days with different SP and SF dosages are shown in Figs. 3 and 4.

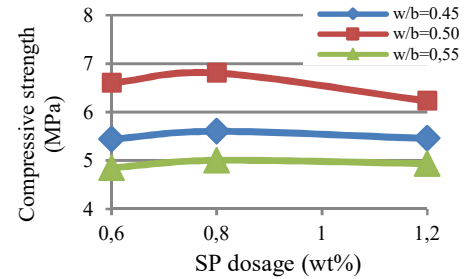

Figure 3: Influence of SP on grout compressive strength at 28 days.

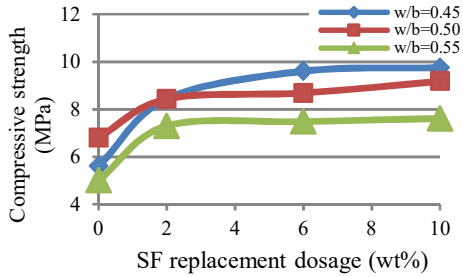

Figure 4: Influence of $\mathrm{SF}$ dosage on grout compressive strength at 28 days

Based on the results obtained, it is possible to detect that the optimum SP dosage, from a strength point of view, corresponds also to the best fresh grout behaviour (i.e. $\mathrm{SP}=0.8 \%$ ). Thus, it can be stated that $\mathrm{SP}$ addition was found to be useful for the increment of grout compressive strength; however, SP dosage above $0.8 \%$ there are any strength improvement. In fact, the SP does not react by a chemical action on hydrated products; it affects the microstructure of the grout, and changes the morphology and size of lime hydration products [16]. This means that an optimisation of the grout composition in the fresh state leads to a robust grout microstructure that beneficially influence hardened properties. The examination of the microstructure on grout fractured surface at the maturity age of 7 days through scanning electron microscopy (SEM) shows that, instead of larger and well-defined crystals, smaller crystals are formed (see Fig. 5). It can be observed that there is a decreasing of compressive strength with an increase of water dosage, as expected. However, an interesting aspect can be noticed in Fig. 3, which is the fact that the highest compressive strength values were obtained for the $\mathrm{w} / \mathrm{b}$ ratio of 0.50 and SP dosage of $0.8 \%$. The authors believe that this increase in compressive strength can result from the coupled effect of a suitable w/b ratio of 0.50 together with the SP action, which provides better particles dispersion and therefore a proper lime hydration.
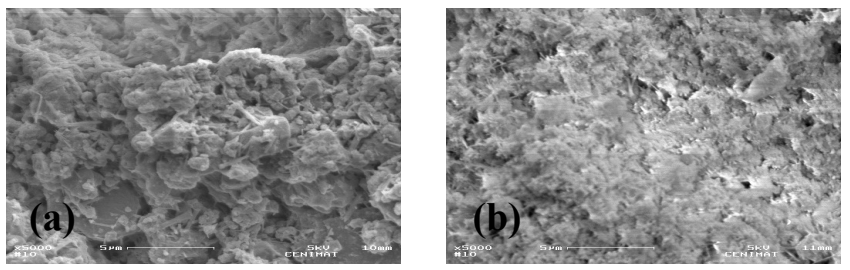

Figure 5: SEM image of 7 days hardened grout at 5000x: (a) without superplasticiser and (b) with superplasticiser.

Concerning the influence of SF on compressive strength at maturity age of 28 days (Fig.4), it can be detected a major difference between the grout without SF and the one with $2 \%$. This behaviour results from the fact that SF leads to pozzolanic 
reactions, by means of reaction with $\mathrm{Ca}(\mathrm{OH})_{2}$, resulting in the formation of additional calcium silicate hydrate (C-S-H) structures. However, for SF dosages higher than $2 \%$ there are no significant improvement on compressive strength. This means that SF replacement up to $2 \%$ can be considered acceptable from the fresh and hardened performance point of view.

Taking into account all these previous results and the fact that the goal was to develop a high performance hydraulic lime-based grout using partial replacement of lime by SF in the presence of polycarboxylate-based SP, it was decided to select the following grout composition: SF dosage of $2 \%$ and SP dosage of $0.8 \%$. At this point, concerning the fresh and hardened state, it was decided to keep the $\mathrm{w} / \mathrm{b}$ ratio equal to 0.50 , since this $\mathrm{w} / \mathrm{b}$ ratio allows a plenty lime hydration and a proper rheological behaviour [17]. The following step was taken in order to identify the suitable environmental temperature from a fresh and hardened grout behaviour point of view.

\subsection{Rheological measurements}

This test aims to contribute to better understand the flow behaviour that hydraulic lime grout presents under different environmental temperatures. Thus, the hydraulic lime grout with SF of $2 \%$, SP dosage of $0.8 \%$ and $w / b$ ratio of 0.50 was tested at different temperatures (from 5 to $40^{\circ} \mathrm{C}$ ) and its flocculation area, as well as some rheological parameters (yield stress and plastic viscosity) were calculated.

The rheological procedure applied enabled the determination of flocculation area for each temperature test. For flocculation phenomenon, the area below of the flow curve in the range $300 \mathrm{~s}^{-1}$ to $0 \mathrm{~s}^{-1}$ indicates the energy that is required to build-up the grout microstructure. This phenomenon is particularly important, since during grout injection inside masonry inner core the flow tends to stop enabling an increase of the particle flocculation phenomenon, thus a lower flocculation area is desired. Note, however, that this area cannot be characterised as a material parameter in the same way as a rheological parameter (like viscosity). This area depends on the shear history of the material and degree of dispersion. However, the same experimental procedure was adopted to ensure the same test conditions in order to allow a comparison of the results. Fig. 6 presents flocculation areas according to the procedure adopted.

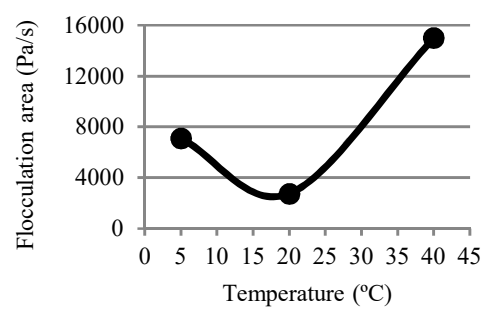

Figure 6: Flocculation area of grouts with $\mathrm{SF}=2 \%+\mathrm{SP}=0.8 \%$ and $\mathrm{w} / \mathrm{b}=0.50$

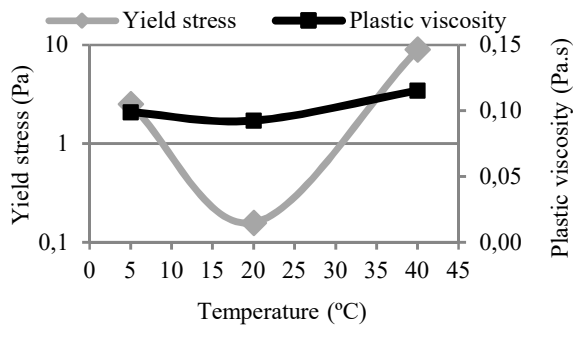

Figure 7: Yield stress and viscosity values of grouts with $\mathrm{SF}=2 \%+\mathrm{SP}=0.8 \%$ and $\mathrm{w} / \mathrm{b}=0.50$.

According to the results presented in Fig. 6, it seems that there is a decrease of flocculation area with an increase in temperature up to $20^{\circ} \mathrm{C}$; however, flocculation area starts significantly to increase for temperatures higher than $20^{\circ} \mathrm{C}$. This means that the temperature of $20^{\circ} \mathrm{C}$ can be pointed out as optimum environmental temperature. This behaviour can be attributed to two different factors; when the 
temperature increases leads to faster hydration reactions and higher flocculation area, as expected the hydration affects the thixotropic behaviour. However, for lower temperatures (such as $5^{\circ} \mathrm{C}$ ) the grout temperature begins to approach to the water freezing point, which leads to formation of strong hydrogen bonds. Moreover, at the molecular level, temperature is related to the random motions of the particles (Brownian motion). This means that for lower temperatures, the molecular agitation decreases (grout particles are closer to each other), thus a less freedom state causes a higher flocculation area (quicker microstructure build up). In addition, it is also possible that, at lower temperatures a decrease in the intensity of the dispersion mechanism of SP molecules may occur, caused by changes in the spatial arrangement of the adsorbed SP [5, 18].

For the steady state analysis, the modified Bingham model eqn. (1) was chosen. Fig. 7 presents the values of yield stress and plastic viscosity for different grout temperatures. From the results presented above, it is clear that the rheological parameters decrease with increase of temperature in the range of 5 to $20^{\circ} \mathrm{C}$. Moreover, for a grout temperature higher than $20^{\circ} \mathrm{C}$ a significant workability loss can be detected (i.e. an increase of yield stress and plastic viscosity); however the effect of temperature over the yield stress was more significant than over the plastic viscosity. Thus, based on achieved results it can be stated that the environmental temperature of $20^{\circ} \mathrm{C}$ leads to the best grout rheological behaviour. Similar trends were reported by Bras et al [11], who also obtained a better rheological performance for fresh hydraulic lime grout temperature of $20^{\circ} \mathrm{C}$. Note, however, that these experimental results are not directly comparable since the experimental work carried out by Bras et al does not consider the use of SP. The decrease of yield stress and plastic viscosity with the increase of temperature from $5^{\circ} \mathrm{C}$ to $20^{\circ} \mathrm{C}$ it can be attributed to an increase in the Brownian motion of the particles, as previously mentioned. However, this thermal agitation is countered by faster reaction kinetics of the lime hydration caused by high temperatures, according to the PFI-theory [19] with the evolution of hydration reactions most of the binder particles start to be permanently connected between each other (physical bonds are not reversible) and therefore the grout cannot flow, not even with the effort of re-agitation, which leads to workability loss.

\subsection{Thermogravimetry}

Considering that the formation of the basic microstructure of cementitious mixes take place between 7 and 28 days of maturity [20], the thermogravimetric analysis has been performed on grouts at maturity age of 7, 14 and 28 days. All the samples were maintained at different and controlled environmental conditions, until the age of the TG analysis. Figs. 8, 9 and 10 show the DTG curves of grouts with SF content of $2 \%$, SP dosage of $0.8 \%$ and $\mathrm{w} / \mathrm{b}$ ratio of 0.50 at temperature of 5,20 and $40^{\circ} \mathrm{C}$, respectively. It can be observed that the DTG curves of all grout samples show three main mass loss (peaks): (i) the first mass loss, located between 100 and $200^{\circ} \mathrm{C}$, is the result of dehydration reactions of several hydrates (C-S-H, ettringite, etc.); (ii) the second major mass loss, observed at $450-580^{\circ} \mathrm{C}$, corresponds to the dehydroxylation of $\mathrm{Ca}(\mathrm{OH})_{2}$ (also called portlandite); (iii) the third loss of mass appears at 800 $1000^{\circ} \mathrm{C}$ and corresponds to the decarbonation of $\mathrm{CaCO}_{3}$ (also called calcite). 


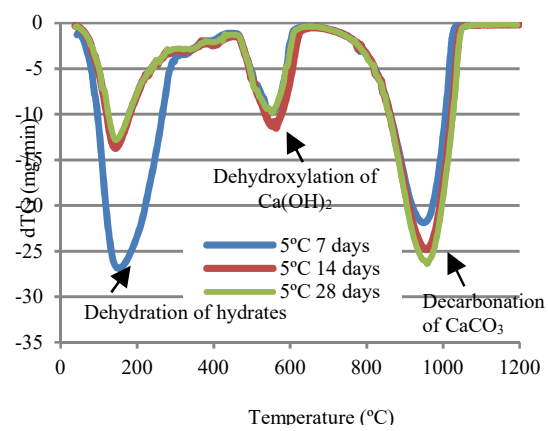

Figure 8: DTG curve of grout with $\mathrm{SF}=2 \%$ $+\mathrm{SP}=0.8 \%$ and $\mathrm{w} / \mathrm{b}=0.50$. Grout sample was maintained at $5^{\circ} \mathrm{C}$ until the age of 7,14 and 28 days.

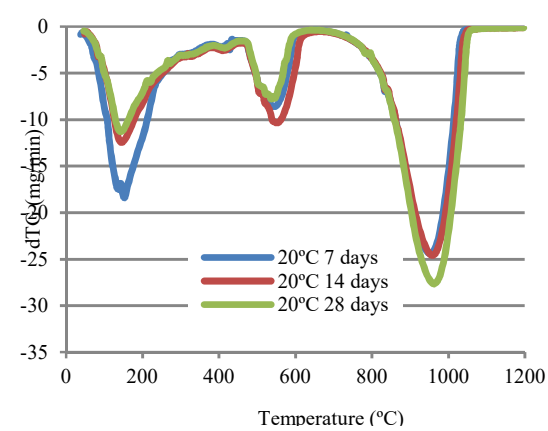

Figure 9: DTG curve of grout with $\mathrm{SF}=2 \%$ $+\mathrm{SP}=0.8 \%$ and $\mathrm{w} / \mathrm{b}=0.50$. Grout sample was maintained at $20^{\circ} \mathrm{C}$ until the age of 7,14 and 28 days.

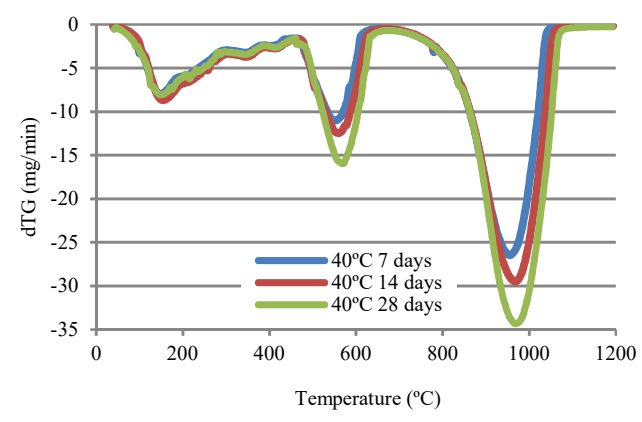

Figure 10: DTG curve of grout with $\mathrm{SF}=2 \%+\mathrm{SP}=0.8 \%$ and $\mathrm{w} / \mathrm{b}=0.50$. Grout sample was maintained at $40^{\circ} \mathrm{C}$ until the age of 7,14 and 28 days.

Analysing the TGA curves, it is clear that grouts mixed and cured at different environmental temperatures present different hydration kinetics between each other. The peak of the dehydration of the C-S-H decreases with the increase of the environmental temperature and tend to disappear with ageing, as expected. On the other hand, the first peak increases at low environmental temperatures suggesting a higher content of water, consequence of hydration reactions being delayed. The second peak around $500^{\circ} \mathrm{C}$ as result of the dehydroxylation of $\mathrm{Ca}(\mathrm{OH})_{2}$ shows an increase on mass loss, which is the opposite of what is expected. In fact, what would be expected from aging should be a decrease of $\mathrm{Ca}(\mathrm{OH})_{2}$ content with the increase of decarbonation reaction (carbonate comes from the portlandite transformation into calcite). However, according to Lanas et al. [21] the $\mathrm{C}_{3} \mathrm{~S}$ hydration at early periods contributes to the production of new $\mathrm{Ca}(\mathrm{OH})_{2}$ and, therefore, the amount of portlandite increase. However, the authors are aware that the hydration reactions as well as the products formed should be followed and complemented by simultaneous $\mathrm{X}$-ray diffraction analysis (XDR) to reach a more detailed conclusion.

From the above results, it can be observed that decarbonation of $\mathrm{CaCO}_{3}$ increase significantly with increase of environmental temperature. The high $\mathrm{CaCO}_{3}$ content (Fig. 10) can be explained due to the curing conditions employed being favourable to its development; this means that high environmental temperatures and low relative humidity lead to a raise of carbonation and therefore a higher $\mathrm{CO}_{2}$ content, because 
the dry pores allow the $\mathrm{CO}_{2}$ penetration in the grout matrix [21]. These results corroborate the conclusions other studies in the concrete field [22], these authors stated that dry environments provide the development of high mechanical strength, which is caused by coupled reactions of hydration and carbonation. It is clear that, from a comprehensive point of view, these environmental conditions are difficult to be ensured inside the masonry inner core; in addition to the fact these conditions are extremely harmful during grout injection, as demonstrated above by rheological measurements.

\section{Conclusions}

According to the results of flow time and strength an optimum grout composition can be proposed, for hydraulic lime-based grout, as following: SF replacement dosage of $2 \%$, SP dosage of $0.8 \%$ and $\mathrm{w} / \mathrm{b}$ ratio of 0.50 . Concerning the rheological results, a significant workability loss was observed if the grout temperature increased beyond $20^{\circ} \mathrm{C}$. Moreover, it was detected that when the temperature decreases (below $20^{\circ} \mathrm{C}$ ) the fresh grout properties becomes worse, which results from the fact that molecular agitation decreases at lower temperatures causing a higher flocculation and therefore a workability loss. Nevertheless, according to the achieved results it can be considered that the grout temperature around $20^{\circ} \mathrm{C}$ leads to a proper rheological behaviour, which should be ensured so that the grout may flow correctly inside the masonry core. The thermogravimertic results, suggest that high temperature and low relative humidity are favourable curing conditions for the development of both hydration and carbonation reactions.

These results show that the effect of temperature is not negligible for both fresh and hardened grout performance; this means that during a practical injection (in the field) a proper choice of environmental temperature (by choosing the correct season of the year to do it) will allow to get an improvement of injection capacity but also in terms of strength development. The authors recognise that these results should not be generalised, since the influence of the analysed parameters will depend on other factors that have not been considered in this study, such as type of SP, mineralogical composition of hydraulic lime, among others. It is clear, however, that additional characterizations of the flow and injection processes are needed. In any case, this investigation demonstrated the importance of a correct grout design and a suitable processing temperature in the improvement of fresh and hardened properties of hydraulic lime-based grouts.

\section{Acknowledgments}

This paper is part of the research project PTDC/ECM/104376/2008, founded by FCT/MCTES, Portugal. The authors would like to express their thanks to Eng. Ana Santos for her help with materials preparation and experimental work.

\section{References}

[1] Valluzzi, M. R., Requirements for the choice of mortar and grouts for consolidation of three-leaf stone masonry walls. Proc. of the Int. RILEM Workshop on Repair Mortar for Historic Masonry, Delft, Netherlands, 2005.

[2] Vintzileou E.,Three-leaf masonry in compression, before and after grouting: a review of literature. International Journal of Architectural Heritage, 5, pp. 513-538, 2011. 
[3] Baltazar L.G., Henriques F.M.A., Jorne F., Optimisation of flow behaviour and stability of superplasticized fresh hydraulic lime grouts through design of experiments. Construction and Building Materials, 35, pp. 838-845, 2012.

[4] Eriksson M., Friedrich, M., Vorschulze, C., Variations in the rheology and penetrability of cement-based grouts-an experimental study, Cement and Concrete Research, 34, pp. 1111-1119, 2004.

[5] Fernàndez-Altable V., Casanova I., Influence of mixing sequence and superplasticiser dosage on the rheological response of cement pastes at different temperatures. Cement and Concrete Research, 36, pp. 1222-1230, 2006.

[6] Baltazar L.G., Henriques F.M.A., Jorne F., Hydraulic lime grouts for masonry injection effects of admixtures on the fresh grout properties. Proc. of the 8th Int. Conf. on Structural Analysis of Historical Constructions, Wroclaw, Poland, 2012.

[7] Martins, R.M. and Bombard, A.J.F., Rheology of fresh cement paste with superplasticizer and nanosilica admixtures studied by response surface methodology. Materials and Structures, 45, pp. 905-921, 2012.

[8] Vickan, H., Rheology and reactivity of cementitious binders with plasticizers. PhD Thesis at Norwegian University of Science and Technology, 2005.

[9] Roussel N., Cussigh F., Distinct-layer casting of SCC: the mechanical consequences of thixotropy, Cement Concrete Research, 38, pp. 624-632, 2008.

[10] Binda L., Modena C., Baronio G., Abbaneo S., Repair and investigation techniques for stone masonry walls. Construction and Building Materials, 11(3), pp. 133-142, 1997.

[11] Bras A., Henriques F.M.A., Cidade M.T., Effect of environmental temperature and fly ash addition in hydraulic lime grout behaviour. Construction and Building Materials, 24, pp. $1511-1517,2010$

[12] Jorne, F., Henriques, F.M.A., Baltazar, L.G., Grout injection in porous media with different internal structures. Proc. Of the 14th Int. Conf. Structural Faults \& Repair, Scotland, 2012

[13] Barnes, H.A., A handbook of elementary rheology. University of Wales, 2000.

[14] Aïtcin P.C. High performance concrete. London: E \& FN Spon, 1998.

[15] Banfill P.F.G., Additivity effects in the rheology of fresh concrete containing waterreducing admixtures. Construction and Building Materials, 25, pp. 2955-2960, 2011.

[16] Demir I. and Baspinar M.S., Effect of silica fume and expanded perlite addition on the technical properties of the fly ash-lime-gypsum mixture. Construction and Building Materials, 22, pp. 1299-1304, 2008.

[17] Miltiadou A.E., Contribution à l'étude des coulis hydrauliques pour la réparation et le renforcement des structures et des monuments historiques en maçonnerie. Doctoral de l'École National de Ponts et Chaussées, Paris, France, 1990.

[18] Billberg P., Form pressure generated by self-compacting concrete-influence of thixotropy and structural behaviour at rest. Dissertation, School of Architecture and the Built Environment, Royal Institute of Technology, Sweden, 2006.

[19] Wallevik JE., Rheological properties of cement paste: thixotropic behavior and structural breakdown. Cement Concrete Research, 39, pp. 14-29, 2009.

[20] Ramachandran, V. S., Beaudoin J.J., Handbook of analytical techniques in concrete science and technology. Noyes Publications / William Andrew Publishing, LLC, Norwich, New York, 2001.

[21] Lanas J., et al, Mechanical properties of natural hydraulic lime-based mortars. Cement and Concrete Research, 34, pp. 2191-2201, 2004.

[22] Metha, P. Kumar.; Monteiro, Paulo J.M., Concrete: Microestructure, properties and materials. Third edition, Mc Graw Hill, 2006. 